\title{
An Examination of Concentration and Mental Toughness in Professional Basketball Players
}

\author{
Çağatay Dereceli \\ Correspondence: Çağatay Dereceli, Aydın Adnan Menderes University, Faculty of Sport Sciences, Turkey.
}

Received: November 13, 2018

Accepted: December 3, 2018 Online Published: December 6, 2018

doi:10.11114/jets.v7i1.3841

URL: https://doi.org/10.11114/jets.v7i1.3841

\begin{abstract}
This study was carried out to investigate the concentration and mental toughness of professional basketball players. A total of 290 professional basketball players aged 16-26 years who played in the Turkish Basketball First and Second Leagues participated in the study. The "Sport Mental Toughness Questionnaire (SMTQ-14)" developed by Sheard et al. (2009) was used to determine mental toughness levels of the basketball players participating in the study, and the "Letter Cancellation Task" scale developed by Kumar and Telles (2009) was used to determine their concentration levels. Data were analyzed by using the Kolmogorov-Smirnov test, an independent samples t-test, and one-way analyses of variance (ANOVA).

Results show that the concentration ability of the basketball players did not significantly differ in terms of gender, age and sports age. There were statistically significant differences in overall mental toughness, confidence and control. The players' mental toughness and confidence scores differed significantly based on sports age. It is interesting to find that overall mental toughness was higher in the basketball players with a sports age of 1-5 years. According to their positions in the play, the players' concentration ability was found to be significantly different between guards and pivots in favor of the guards. The concentration ability of the players playing at the guard position was higher than that of the players playing at other positions. Overall mental toughness and its sub-dimensions had no significant differences according to the positions. However, it is striking that overall mental toughness scores and its sub-dimension scores were high in guards and pivots.
\end{abstract}

Keywords: basketball players, concentration, mental toughness

\section{Introduction}

Basketball is a common sport fondly followed by the vast majority of the world, finding its participants in almost every society and age group. The majority of the game takes place in an anaerobic (oxygen-free metabolism) environment, because the game is played at a high speed and occurs with continuous and sudden changes between movement patterns such as leaping, sudden runs and sudden switches of direction (Hoffman and Maresh, 2000; Crisafulli et al., 2002). It is crucial that the player has a good anaerobic toughness, rapidity, and a high level of agility in order to keep his or her ability at top level for 40 minutes while he or she carries out movements that require rapid acceleration and deceleration, direction changes, sideways shifts, leaps (rebounds, blocks and shoots), quick runs (sprints) either with or without the ball in an area which is $28 \mathrm{~m}$ long and $15 \mathrm{~m}$ wide (Delextrat and Cohen, 2009). The player needs to be ready and active in receiving and throwing passes, in shooting, dribbling, and rebounding at any time due to the fact that the ability to move and decide in basketball is momentary (Muratl1, Toraman and Çetin, 2000). Research shows that elite basketball players have different structural and biomotor abilities when assessed according to their positions in the play. Studies have found similar results on structural differences of players. Pivot players have been shown to be taller and heavier than forward and guard players (Ostojic, Mazic and Dikic, 2006; Latin, Berk and Baechle, 1994). Krane and Williams (2010) proposed an 11-item template of psychological abilities that should be found in elite athletes who are getting ready for the Olympics. Based on this work, Cox (2012) has determined the psychological characteristics of elite athletes. Although they may vary depending on the sports branch, they can be listed as follows: suitable personality characteristics; having a controllable inner focus for success and failure; a high level of self-confidence and belief in the ultimate achievement; intrinsic motivation; a strong goal-oriented dominance for athletic success; a full concentration on an existing task; an ability to control emotion and excitement; strong coping skills to cope with difficulties faced; setting challenging goals and having the ability to formulate plans to achieve them; the ability to use self-talk, imagination, self-control and other psychological methods to gain confidence and motivation; and mental toughness 
(Cox, 2012). Concentration is defined as the mental effort that one is willing to put on the most important thing in any situation (Moran, 2004). Concentration is the ability to focus on relevant environmental cues (Weinberg and Gould, 2015). A highly concentrated athlete tries to do his job in the best possible way, speeds up the process of learning new skills, improves his self-confidence, controls stress and anxiety by using his experience and focuses on the factors that are in control. Internal factors that influence concentration are negative thoughts, fears, sadness, and worries. External factors include umpire decisions, spectators, competitor athletes, weather conditions and media (www.scribd.com, 2018). Mental toughness is defined by concepts such as coping with pressure and difficulties effectively, recovery after failures, challenge, being insistent and not giving up, competition with himself and with others, being unaffected or flexible in adverse situations, having a firm belief in taking control of his future, showing improvement under pressure and having superior mental skills (Clough, Earle and Sewell, 2002; Middleton et al., 2004; Jones, Hanton and Connaughton, 2002; Bull et al., 2005; Golby, Sheard and Lavallee, 2003; Thelwell, Weston and Greenlees, 2005; Luthans, 2002). Control, as one of the sub-dimensions of mental toughness, is the ability to maintain performance without being brought under control by another external factor while trying to manage multiple situations. The confidence sub-dimension is the ability to sustain self-belief despite failures and not to quail before opponents. The stability sub-dimension is dedicating oneself to pursue goals and striving to reach the goals despite difficulties. It is closely related with the effort and purpose of achieving predetermined goals despite difficulties. The struggle sub-dimension is the ability to see potential threats as a personal development opportunity and to comprehend the ever-evolving environmental change (Clough, Earle and Sewell, 2002). Mentally-tough athletes have the tendency to be individuals who are highly competitive; determined; self-motivated; able to maintain concentration in situations that cause pressure and can cope effectively with such situations; resist increasing difficulties; and can maintain a high level of self-belief even after failures (Crust and Clough, 2011). Concentration and mental toughness abilities are known to be important components of athlete performance. In light of this information, the aim of this study was to investigate mental toughness and concentration abilities in professional basketball players.

\section{Material and Method}

In order to investigate concentration and mental toughness abilities in professional basketball players, a total of 290 players aged 16-26 years - 148 females and 142 males - who were playing in the Turkish Basketball First and Second Leagues were included in the study. The "Sport Mental Toughness Questionnaire (SMTQ-14)" developed by Sheard et al. (2009) was used to determine the mental toughness levels of the basketball players participating in the study, and the "Letter Cancellation Task" scale developed by Kumar and Telles (2009) was used to determine the concentration level.

The Concentration Scale: The Letter Cancellation Task as used by Kumar and Telles (2009) was used to measure the concentration levels of the participants. The task consisted of a block of randomly placed letters in 14 columns and 22 rows with six assigned letters listed at the top of the page. The participants were required to cancel the letters within the block in 90 seconds. A score of concentration on the Letter Cancellation Task was calculated for each participant by counting the number of correctly canceled letters within the grid. This score represented the speed and accuracy of the participant's completion and therefore his or her concentration level (Kumar and Telles, 2009).

The Sports Mental Toughness Questionnaire (SMTQ): In order to determine the level of mental toughness in the sports environment, "Sports Mental Toughness Questionnaire (SMTQ-14)" was used. The questionnaire was developed by Sheard et al. (2009) and consisted of 14 items. In addition to general mental stability, the scale included three sub-dimensions (Confidence, Continuity, and Control) with 4-point Likert type questions ( $1=$ False, $4=$ Fully True). The Cronbach Alpha values for the sub-dimensions of the original scale were .81 for confidence; .74 for continuity; and .71 for control. The three sub-dimensions of SMTQ are defined as follows. Confidence: It is believing in one's own talents to reach a goal in challenging situations and thinking better than competitors (Items 1, 5, 6, 11, 13, and 14). Control: It is being cool, controlled and comfortable under pressure or in unexpected situations (Items 2, 4, 7, and 9). Continuity: It is taking responsibility, concentration and struggling to achieve objectives (Items 3,8 , 10, and 12) (Sheard, Golby and Van Wersch, 2009; Sheard, 2013).

\section{Statistical Analysis of Data}

Data obtained from the basketball players were analyzed in the SPSS 22.0 package program. The normality of the data was tested using the Kolmogorov-Smirnov test. Since the data were found to be normally distributed, independent samples t-tests were used in cases where two independent variables were compared and one-way analyses of variance (ANOVA) were used to calculate the differences between three and more independent variables. Moreover, the frequency distributions of the basketball players who participated in the study were calculated according to their positions by gender. 


\section{Results}

Table 1. Distribution of the Basketball Players by Position and Gender

\begin{tabular}{cccccc}
\hline \multirow{2}{*}{ Position } & \multicolumn{3}{c}{ Gender } & Male \\
\cline { 2 - 5 } & & Female & $\mathbf{0}$ & $\boldsymbol{N}$ & $\mathbf{\%}$ \\
\cline { 2 - 5 } & $\boldsymbol{N}$ & 27.0 & 28 & 19.7 \\
\hline Guard & 40 & 14.2 & 26 & 27.3 \\
\hline Point guard & 21 & 26.4 & 39 & 18.3 \\
\hline Forward & 39 & 14.9 & 26 & 16.2 \\
\hline Power forward & 22 & 17.6 & 23 & $\mathbf{1 0 0}$ \\
\hline Pivot & 26 & $\mathbf{1 0 0}$ & $\mathbf{1 4 2}$ & \\
\hline Total & $\mathbf{1 4 8}$ & &
\end{tabular}

Table 1 shows the frequency distributions of the basketball players participating in the study according to their positions and gender.

Table 2. Comparison of the Mental Toughness of the Basketball Players by Gender

\begin{tabular}{|c|c|c|c|c|c|c|c|}
\hline \multirow{2}{*}{ Variables } & \multirow{2}{*}{ Gender } & \multirow{2}{*}{$N$} & \multirow{2}{*}{ M } & \multirow{2}{*}{ SD \pm} & \multirow{2}{*}{ SE } & \multicolumn{2}{|c|}{ t test } \\
\hline & & & & & & t & p \\
\hline \multirow{2}{*}{ Concentration } & Female & 148 & 37.56 & 13.44 & 1.10 & .866 & .387 \\
\hline & Male & 142 & 36.32 & 10.65 & .89 & & \\
\hline \multirow{2}{*}{ Overall mental toughness } & Female & 148 & 34.76 & 6.82 & .56 & 1.396 & .164 \\
\hline & Male & 142 & 33.82 & 4.26 & .35 & & \\
\hline \multirow{2}{*}{ Confidence } & Female & 148 & 13.97 & 2.37 & .19 & .348 & .728 \\
\hline & Male & 142 & 13.86 & 3.13 & 26 & & \\
\hline \multirow{2}{*}{ Control } & Female & 148 & 12.23 & 5.94 & .48 & 1.880 & .061 \\
\hline & Male & 142 & 11.26 & 1.59 & .13 & & \\
\hline \multirow{2}{*}{ Continuity } & Female & 148 & 8.84 & 2.05 & .16 & .631 & .529 \\
\hline & Male & 142 & 8.70 & 1.70 & .14 & & \\
\hline
\end{tabular}

As seen in Table 2, there was no statistically significant difference between the female and male basketball players in terms of concentration, overall mental toughness and mental toughness sub-dimensions ( $p<.05$ ). However, female players had higher mean scores on concentration and overall mental toughness than male players.

Table 3. Comparison of the Mental Toughness of the Basketball Players by Age

\begin{tabular}{|c|c|c|c|c|c|c|c|c|}
\hline Variables & & Age group & $\bar{N}$ & $\mathbf{X}$ & SD \pm & $\mathbf{F}$ & $\mathbf{p}$ & Difference \\
\hline \multirow{4}{*}{ Concentration } & $\mathbf{1}$ & $16-20$ years old & 114 & 37.60 & 12.82 & .938 & .392 & \\
\hline & 2 & $21-25$ years old & 97 & 35.58 & 11.96 & & & \\
\hline & 3 & 26 years and older & 79 & 37.72 & 11.37 & & & \\
\hline & 4 & Total & 290 & 36.96 & 12.15 & & & \\
\hline \multirow{4}{*}{$\begin{array}{l}\text { Overall mental } \\
\text { toughness }\end{array}$} & $\mathbf{1}$ & $16-20$ years old & 114 & 35.51 & 7.58 & 4.426 & $013^{* *}$ & \multirow{4}{*}{$1-2$} \\
\hline & 2 & $21-25$ years old & 97 & 33.36 & 4.10 & & & \\
\hline & 3 & 26 years and older & 79 & 33.68 & 3.63 & & & \\
\hline & 4 & Total & 290 & 34.29 & 5.71 & & & \\
\hline \multirow{4}{*}{ Confidence } & $\mathbf{1}$ & $16-20$ years old & 114 & 14.51 & 3.77 & 4.453 & $.012^{*}$ & \multirow{4}{*}{$\begin{array}{l}1-2 \\
1-3\end{array}$} \\
\hline & 2 & 21-25 years old & 97 & 13.60 & 1.78 & & & \\
\hline & 3 & 26 years and older & 79 & 13.46 & 1.77 & & & \\
\hline & 4 & Total & 290 & 13.92 & 2.77 & & & \\
\hline \multirow{4}{*}{ Control } & 1 & $16-20$ years old & 114 & 12.61 & 6.59 & 3.673 & $.027^{*}$ & \multirow{4}{*}{$1-2$} \\
\hline & 2 & $21-25$ years old & 97 & 11.11 & 1.82 & & & \\
\hline & 3 & 26 years and older & 79 & 11.30 & 1.76 & & & \\
\hline & 4 & Total & 290 & 11.76 & 4.40 & & & \\
\hline \multirow{4}{*}{ Continuity } & 1 & $16-20$ years old & 114 & 8.78 & 2.02 & .457 & .633 & \\
\hline & 2 & $21-25$ years old & 97 & 8.65 & 1.80 & & & \\
\hline & 3 & 26 years and older & 79 & 8.92 & 1.81 & & & \\
\hline & 4 & Total & 290 & 8.78 & 1.89 & & & \\
\hline
\end{tabular}

*Significance at .05 level

As seen in Table 3, there was no significant difference in the concentration ability according to age groups ( $\mathrm{p}<.05$ ). Overall mental toughness, confidence and control scores of the players differed significantly depending on age groups $(\mathrm{p}<.05)$. The mean overall mental toughness score of the 16-20-year-old basketball players was 35.51 \pm 7.58 , while that of the 21-25-year-old basketball players was 33.36 \pm 4.10 . It is interesting that the 16-20-year-old basketball players had higher overall mental toughness scores.

The mean confidence score was found to be 14.51 \pm 3.77 in the 16-20-year-old basketball players, 13.60 \pm 1.78 in the 21-25-year-old basketball players, and $13.46 \pm 2.77$ in the basketball players who were 26 years old or older. We can say that the ability to sustain self-belief despite failures and not to quail before opponents was higher in the 16-20-year-old basketball players.

The mean control score of the 16-20-year-old basketball players was 12.61 \pm 6.59 , while that of the 21-25-year-old basketball players was $11.11 \pm 1.82$. We can say that the ability to maintain performance without being brought under control by another external factor while trying to manage multiple situations was higher in the 16-20-year-old basketball players. 
Table 4. Comparison of the Mental Toughness of the Basketball Players by Spots Age

\begin{tabular}{|c|c|c|c|c|c|c|c|c|}
\hline Variables & & Sports age & $N$ & $\mathbf{X}$ & SD \pm & $\mathbf{F}$ & $\mathbf{p}$ & Difference \\
\hline \multirow{5}{*}{ Concentration } & 1 & $1-5$ years & 31 & 34.03 & 15.1 & 1.613 & .187 & \multirow{10}{*}{$\begin{array}{l}1-2 \\
1-3 \\
1-4\end{array}$} \\
\hline & 2 & $6-10$ years & 106 & 38.52 & 11.3 & & & \\
\hline & $\overline{3}$ & $11-15$ years & 91 & 35.65 & 11.8 & & & \\
\hline & 4 & 16 years or older & 62 & 37.66 & 11.9 & & & \\
\hline & 5 & Total & 290 & 36.96 & 12.1 & & & \\
\hline \multirow{5}{*}{$\begin{array}{l}\text { Overall mental } \\
\text { toughness }\end{array}$} & 1 & $1-5$ years & 31 & 38.00 & 9.45 & 6.769 & $.000^{*}$ & \\
\hline & 2 & $6-10$ years & 106 & 34.69 & 6.20 & & & \\
\hline & 3 & $11-15$ years & 91 & 32.96 & 3.88 & & & \\
\hline & 4 & 16 years or older & 62 & 33.73 & 3.45 & & & \\
\hline & 5 & Total & 290 & 34.29 & 5.71 & & & \\
\hline \multirow{5}{*}{ Confidence } & 1 & $1-5$ years & 31 & 15.26 & 2.55 & 4.849 & $.003^{*}$ & \multirow{5}{*}{$\begin{array}{l}1-3 \\
1-4\end{array}$} \\
\hline & 2 & $6-10$ years & 106 & 14.26 & 3.71 & & & \\
\hline & 3 & $11-15$ years & 91 & 13.46 & 1.96 & & & \\
\hline & 4 & 16 years or older & 62 & 13.34 & 1.45 & & & \\
\hline & 5 & Total & 290 & 13.92 & 2.77 & & & \\
\hline \multirow{5}{*}{ Control } & 1 & $1-5$ years & 31 & 13.32 & 7.33 & 2.364 & .071 & \\
\hline & 2 & $6-10$ years & 106 & 12.06 & 5.70 & & & \\
\hline & 3 & $11-15$ years & 91 & 11.04 & 1.65 & & & \\
\hline & 4 & 16 years or older & 62 & 11.50 & 1.82 & & & \\
\hline & 5 & Total & 290 & 11.76 & 4.40 & & & \\
\hline \multirow{5}{*}{ Continuity } & 1 & $1-5$ years & 31 & 9.42 & 1.85 & 2.197 & .089 & \\
\hline & 2 & $6-10$ years & 106 & 8.80 & 2.10 & & & \\
\hline & 3 & $11-15$ years & 91 & 8.45 & 1.65 & & & \\
\hline & 4 & 16 years or older & 62 & 8.89 & 1.79 & & & \\
\hline & 5 & Total & 290 & 8.78 & 1.89 & & & \\
\hline
\end{tabular}

As seen in Table 4, there was no significant difference in the concentration ability according to sports age ( $\mathrm{p}<.05)$. Overall mental toughness and control scores of the players differed significantly based on sports age $(\mathrm{p}<.05)$. The mean overall mental toughness of the players whose sports age was $1-5$ years was $38.00 \pm 15.1$ while that of the players whose sports age was $11-15$ years was $32.96 \pm 3.88$. It is attention-grabbing that overall mental toughness was higher in the players with a smaller sports age than in the players with a greater sports age. The mean confidence score of the players whose sports age was $1-5$ years was $15.26 \pm 2.55$ while that of the players whose sports age was $11-15$ years was $13.46 \pm 1.96$. We can say that the ability to sustain self-belief despite failures and not to quail before opponents was higher in the basketball players whose sports age was $1-5$ years.

Table 5. Comparison of the Mental Toughness of the Basketball Players by Their Positions in the Play

\begin{tabular}{|c|c|c|c|c|c|c|c|c|}
\hline Variables & & Position & $N$ & $\mathbf{X}$ & SD \pm & $\mathbf{F}$ & $\mathbf{p}$ & Difference \\
\hline \multirow{6}{*}{ Concentration } & 1 & Guard & 68 & 40.21 & 12.9 & 2.575 & .038 & \multirow{6}{*}{$1-5$} \\
\hline & 2 & Point guard & 47 & 37.70 & 11.5 & & & \\
\hline & 3 & Forward & 78 & 36.76 & 11.6 & & & \\
\hline & 4 & Power forward & 48 & 35.71 & 12.4 & & & \\
\hline & 5 & Pivot & 49 & 33.27 & 11.3 & & & \\
\hline & 6 & Total & 290 & 36.96 & 12.1 & & & \\
\hline \multirow{6}{*}{$\begin{array}{l}\text { Overall mental } \\
\text { toughness }\end{array}$} & $\mathbf{1}$ & Guard & 68 & 34.76 & 7.59 & 1.338 & .256 & \\
\hline & 2 & Point guard & 47 & 33.27 & 3.86 & & & \\
\hline & 3 & Forward & 78 & 33.83 & 5.00 & & & \\
\hline & 4 & Power forward & 48 & 34.02 & 3.84 & & & \\
\hline & 5 & Pivot & 49 & 35.65 & 6.61 & & & \\
\hline & 6 & Total & 290 & 34.30 & 5.72 & & & \\
\hline \multirow{6}{*}{ Confidence } & 1 & Guard & 68 & 14.04 & 2.67 & .185 & .946 & \\
\hline & 2 & Point guard & 47 & 13.62 & 2.04 & & & \\
\hline & 3 & Forward & 78 & 13.91 & 4.01 & & & \\
\hline & 4 & Power forward & 48 & 13.96 & 1.86 & & & \\
\hline & 5 & Pivot & 49 & 14.00 & 1.76 & & & \\
\hline & 6 & Total & 290 & 13.92 & 2.77 & & & \\
\hline \multirow{6}{*}{ Control } & 1 & Guard & 68 & 11.91 & 5.22 & .396 & .811 & \\
\hline & 2 & Point guard & 47 & 11.21 & 1.75 & & & \\
\hline & 3 & Forward & 78 & 11.86 & 4.98 & & & \\
\hline & 4 & Power forward & 48 & 11.44 & 1.79 & & & \\
\hline & 5 & Pivot & 49 & 12.20 & 5.67 & & & \\
\hline & 6 & Total & 290 & 11.76 & 4.40 & & & \\
\hline \multirow{6}{*}{ Continuity } & 1 & Guard & 68 & 8.81 & 1.86 & 2.162 & .073 & \\
\hline & 2 & Point guard & 47 & 8.45 & 1.77 & & & \\
\hline & 3 & Forward & 78 & 8.62 & 1.81 & & & \\
\hline & 4 & Power forward & 48 & 8.63 & 1.73 & & & \\
\hline & 5 & Pivot & 49 & 9.45 & 2.19 & & & \\
\hline & 6 & Total & 290 & 8.78 & 1.89 & & & \\
\hline
\end{tabular}

As seen in Table 5, according to player positions, guards and pivots had significantly different concentration scores, in favor of the guards $(\mathrm{p}<.05)$. Overall mental toughness scores and its sub-dimension scores did not significantly differ 
according to player positions ( $\mathrm{p}>.05)$.

The concentration levels of the players were $40.21 \pm 12.9$ at the guard position, $37.70 \pm 11.5$ at the point guard position, $36.76 \pm 11.6$ at the forward position, $35.71 \pm 12.4$ at the power forward position, and $33.27 \pm 11.3$ at the pivot position. The concentration ability of the players playing at the guard position was found to be higher than that of the basketball players playing at other positions. It is attention-grabbing that although there was no significant difference in overall mental toughness and its sub-dimensions according to positions, the guard and pivot players had higher scores.

\section{Discussion and Conclusion}

This research study was carried out in order to investigate the concentration and mental toughness of professional basketball players.

There was no statistically significant difference between the female and male basketball players in terms of concentration, overall mental toughness and sub-dimensions of mental toughness. However, the mean concentration and overall mental toughness scores of the female players were higher than those of the male players (Table 2). In a study titled "Mental toughness and emotional intelligence of professional basketball players in terms of different variables," it was found that mental toughness did not differ according to gender; nevertheless, mental toughness was higher in females than in males (Yazıc1, 2016). There was no significant difference in the concentration ability according to age groups. However, there were statistically significant differences in overall mental toughness, confidence and control according to age groups. The fact that overall mental toughness was higher in the 1620-year-old basketball players than in the other age groups is an attention-grabbing finding. In the confidence sub-dimension of mental toughness, it was found that the ability to sustain self-belief despite failures and not to quail before opponents was higher in the 16-20-year-old basketball players. In the control sub-dimension of mental toughness, it was found that the ability to maintain performance without being brought under control by another external factor while trying to manage multiple situations was higher in the 16-20-year-old basketball players. The reason for older players to have lower mental toughness mean scores is thought to be due to fatigue (Table 3). Fatigue has been found to cause a decreased mental toughness level in a study to determine the acute effect of fatigue resulting from anaerobic exercise on athletes' mental toughness levels (Güleroğlu, 2017). There was no significant difference in the concentration ability according to sports age. Overall mental toughness and control scores of the players were significantly different depending on sports age. The mean overall mental toughness score of the players with a sports age of 1-5 years was the highest $(38.00 \pm 15.1)$. It is worthy to note that the basketball players with a sports age of $1-5$ years had a higher overall mental toughness score. The mean confidence score of the players whose sports age was 1-5 years was the highest $(15.26 \pm 2.55)$. It was found that the ability to sustain self-belief despite failures and not to quail before opponents was higher in the basketball players whose sports age was 1-5 years (Table 4). According to player positions, concentration scores of the guards were significantly different than those of the pivots, favoring the guards. Overall mental toughness and its sub-dimensions did not significantly differ according to player positions. The concentration level was the highest $(40.21 \pm 12.9)$ in the players playing at the guard position. The concentration ability of the players playing at the guard position was higher than that of the basketball players playing at other positions. It is worthy to note that although there was no significant difference between the groups in terms of overall mental toughness and its sub-dimensions, the guard and pivot players had higher scores (Table 5). Research shows that mental toughness can vary from branch to branch and can be influenced by different dynamics (Gucciardi and Gordon, 2009; Bull et al., 2005). According to a study investigating the level of mental toughness of tennis and basketball players, the mental toughness of tennis players was found to be better than that of basketball players (Bülbül, 2015). A positive relationship has been found between emotional intelligence and mental toughness in a study conducted in order to determine the relationship between mental toughness and emotional intelligence in professional basketball players playing in Turkish leagues (Yazıc1, 2016). These research findings support our study.

Results show that the concentration ability of the basketball players did not significantly differ based on gender, age and sports age, but their overall mental toughness, confidence and control scores differed significantly. Overall mental toughness and confidence differed significantly depending on sports age. It is worthy to note that the basketball players with a sports age of 1-5 years had higher overall mental toughness scores. When the basketball players were examined according to their positions in the play, the concentration ability was found to be significantly different between guards and pivots in favor of the guards. The concentration ability of the players playing at the guard position was higher than that of the basketball players playing at other positions. Overall mental toughness and its sub-dimension scores did not differ significantly according to the positions played by the basketball players. However, it is striking that the guard and pivot players scored higher in overall mental toughness and its sub-dimensions.

\section{References}

Bülbül, A. (2015). Examination of psychological durability levels of tennis and basketball players and comparison (Unpublished master's thesis). Gedik University, Institute of Health Sciences, Istanbul, Turkey.

Bull, S. J., Shambrook, C. J., James, W., \& Brooks, J. E. (2005). Towards an understanding of mental toughness in elite English cricketers. Journal of Applied Sport Psychology, 17(3), 209-227. 
https://doi.org/10.1080/10413200591010085

Clough, P. J., Earle, K., \& Sewell, D. (2002). Mental toughness: The concept and its measurement. In I. Cockerill (Ed.), Solutions in sport psychology (pp. 3243). London: Thomson Publishing.

Cox, R. H. (2012). Psychological skills training. In R. H. Cox (Edi), Sport psychology. Concepts and applications. 7th ed. (pp. 297). New York: McGraw-Hill.

Crisafulli, A., Melis, F., Tocco, F., \& Laconi, P. (2002). External mechanical work versus oxidative energy consumption ratio during a basketball field test. Journal of Sports Medicine and Physical Fitness, 42(4), 409-417.

Crust, L., \& Clough, P. J. (2011). Developing mental toughness: From research to practice. Journal of Sport Psychology in Action, 2, 21-32. https://doi.org/10.1080/21520704.2011.563436

Delextrat, A., \& Cohen, D. (2009). Strength, power, speed, and agility of women basketball players according to playing position. The Journal of Strength \& Conditioning Research, 23(7), 1974-1981. https://doi.org/10.1519/JSC.0b013e3181b86a7e

Golby, J., Sheard, M., \& Lavallee, D. (2003). A cognitive behavioral analysis of mental toughness in national rugby league teams. Perceptual and Motor Skills, 96, 455-462.

Gucciardi, D., Gordon, S., \& Dimmock, J. (2008). Towards an understanding of mental toughness in Australian football. Journal of Applied Sport Psychology, 20(3), 261-281. https://doi.org/10.1080/10413200801998556

Güleroğlu, F. (2017). The acute effect of fatigue resulted an anaerobic exercise on athletes' mental toughness level (Unpublished master's thesis). Kahramanmaraş Sütçü İmam University, Institute of Health Sciences, Kahramanmaraş, Turkey.

Hoffman, J. R., \& Maresh, C. M. (2000). Physiology of basketball. In W. E. Garrett \& D. T. Kirkendall (Eds). Exercise and sport sciences reviews (pp. X-Y). Philadelphia: Lippincott Williams \&Wilkins, 733, 1999.

Jones, G., Hanton, S., \& Connaughton, D. (2002). What is this thing called mental toughness? An investigation of elite sport performers. Journal of Applied Sport Psychology, 14(3), 205-218. https://doi.org/10.1080/10413200290103509

Krane, V., \& Williams, J. M. (2010). Psychological characteristics of peak performance. In V. Krane \& J. M. Williams (Eds.). Applied sport psychology: Personal growth peak performance (6th ed.) (pp. 169-220). Boston: McGraw-Hill.

Kumar, S., \& Telles, S. (2009). Meditative states based on yoga texts and their effects on performance of a letter-cancellation task. Perceptual and Motor Skills, 109(3), 679-689. https://doi.org/10.2466/pms.109.3.679-689

Latin, R. W., Berk, K., \& Baechle, T. (1994). Physical and performance characteristics of NCAA division I male basketball players. The Journal of Strength \& Conditioning Research, 8(4), 214-218.

Luthans, F. (2002). Positive organizational behavior: Developing and managing psychological strengths. Academy of Management Executive, 16(1), 57-72.

Middleton, S. C., Marsh, H. W., Martin, A. J., Richards, G. E., \& Perry, C. (2004). Self-research center biannual conference: Discovering mental toughness: A qualitative study of mental toughness in elite athletes, Berlin.

Moran, A. (2004). Sport and exercise psychology: A critical introduction. London: Routledge. https://doi.org/10.4324/9780203380246

Muratl1, S., Toraman, F., \& Çetin, E. (2000). Sportif hareketlerin biyomekanik temelleri. Ankara: MEB.

Ostojic, S. M., Mazic, S., \& Dikic, N. (2006). Profiling in basketball: Physical and physiological characteristics of elite basketball players. Journal of Strength and Conditioning Research, 20(4), 740-744. https://doi.org/10.1519/00124278-200611000-00003

Thelwell, R., Weston, N., \& Greenlees, I. (2005). Defining and understanding mental toughness within soccer. Journal of Applied Sport Psychology, 17(4), 326-332. https://doi.org/10.1080/10413200500313636

Weinberg, R. S., \& Gould, D. (2015). Foundations of sport and exercise psychology (6th Ed.). Champaign, IL: Human Kinetics, pp.372.

Yazıc1, A. (2016). Mental toughness and emotional intelligence of professional basketball players in terms of different variables (Unpublished master's thesis). Gazi University, Institute of Health Sciences, Ankara, Turkey. https://www.scribd.com/document/321496484/Sports-Concentration-2-Arda-Coskun.

\section{Copyrights}

Copyright for this article is retained by the author(s), with first publication rights granted to the journal.

This is an open-access article distributed under the terms and conditions of the Creative Commons Attribution license which permits unrestricted use, distribution, and reproduction in any medium, provided the original work is properly cited. 